\title{
Ammonothermal Bulk GaN Growth and Its Processing
}

\author{
Tadao Hashimoto*, Edward Letts, Daryl Key, \\ Keith Male, Matthew Michaels and Sierra Hoff \\ SixPoint Materials, Inc., 37, Industrial Way 106, Buellton, CA 93427, USA
}

(Received January 6, 2014; accepted May 7, 2014)

Key words: ammonothermal growth, bulk GaN, dislocation density, optical absorption, wafer processing

In this paper, we overview the current progress of ammonothermal GaN growth at SixPoint Materials, Inc. and discuss issues in wafer processing. Bulk GaN crystals grown in small prototype reactors present a high-quality microstructure as well as an improved transparency. The dislocation density of the crystal is on the order of $4.0 \times 10^{4}$ $\mathrm{cm}^{-2}$. The optical absorption coefficient as low as $4 \mathrm{~cm}^{-1}$ at $450 \mathrm{~nm}$ is obtained. Wafer processing techniques, such as wire sawing and chemical mechanical polishing, are one of the challenges in realizing GaN wafers. Crystal cracks are the major and fundamental obstacle in achieving a high-quality surface during wire sawing. The surface quality after chemical mechanical polishing (CMP) is successfully evaluated using X-ray diffraction.

\section{Introduction}

$\mathrm{GaN}$ and related alloys have been applied to commercialize various optoelectronic and electronic devices. Lack of native substrates for group III nitride materials led to the development of heteroepitaxial techniques on nonnative substrates such as sapphire and silicon carbide. In the history of compound semiconductors, no other material system has attained a higher maturity level of heteroepitaxial technology than group III nitrides, yet more superior performance at a lower cost is continuously demanded. A new breakthrough is needed to address the current issues, and the use of bulk GaN crystals, which enable the homoepitaxial growth of GaN-based devices on any preferable orientation, has been regarded as the ultimate solution to many problems associated with heteroepitaxy. However, owing to the high melting point and high equilibrium nitrogen pressure at high temperatures, it is extremely difficult to grow bulk GaN crystals of appreciable size. Currently, hydride vapor phase epitaxy (HVPE) provides the most

*Corresponding author: e-mail: Tadao@spmaterials.com 
practical solution to free-standing GaN wafers with the so-called "quasi-bulk" approach, i.e., the growth of a very thick film of $\mathrm{GaN}$ on a heteroepitaxial substrate by HVPE followed by the removal of the substrate. ${ }^{(1)}$ In addition, people have attempted to grow bulk GaN crystals on quasi-bulk GaN wafers by HVPE..$^{(2,3)}$ Nevertheless, the reduction in dislocation density in GaN crystals grown on quasi-bulk GaN wafers by HVPE seems to have its limitation; current HVPE-grown GaN substrates have a dislocation density on the order of high $10^{5}$ to low $10^{6} \mathrm{~cm}^{-2}$. In addition, HVPE is inherently uneconomical because it utilizes an open-reactor system, which requires a constant flow of reactive gases and Ga precursor.

Several approaches to grow bulk GaN crystals from solutions in closed reactors have been reported, e.g., high-pressure solution growth, ${ }^{(4,5)}$ low-pressure solution growth with flux ${ }^{(6,7)}$ and ammonothermal growth. ${ }^{(8-10)}$ Despite the advantage of scalability over its counterparts, not many research institutes have attempted ammonothermal growth because the growth rate is relatively low, and high-pressure ammonothermal reactors are not commercially available. Since Dwiliński et al. demonstrated bulk GaN with excellent crystal quality, ${ }^{(11)}$ ammonothermal growth has drawn increasing attention from the nitride research community. On the basis of ammonothermal technologies at the University of California, Santa Barbara (UCSB), ${ }^{(12)}$ SixPoint Materials, Inc. has been incorporated to develop an ammonothermal GaN growth method for commercial applications. In this article, we will review and update the current status of ammonothermal GaN growth at SixPoint. After a brief introduction giving general information on the ammonothermal growth method, we will introduce the fundamental characteristics of bulk GaN crystals grown by SixPoint's proprietary ammonothermal method as well as issues in wafer processing techniques, such as wire sawing and chemical mechanical polishing (CMP).

\section{Ammonothermal Growth}

\subsection{Fundamentals of ammonothermal growth}

A crystal growth method using a supercritical solvent is generally called solvothermal growth. Solvothermal growth typically utilizes a high-pressure reactor called the autoclave, which can contain the supercritical solvent at a high pressure and a high temperature. The most successful example of solvothermal growth is the hydrothermal growth of $\alpha$-quartz, in which silica is dissolved in supercritical water and recrystallized on seed crystals. Compared with other crystal growth methods, solvothermal growth is highly scalable. Nowadays, more than 1000 crystals are simultaneously grown in a hydrothermal quartz autoclave. Ammonothermal growth is a type of solvothermal growth using ammonia as a solvent, which is mainly used to grow or synthesize nitride materials. Generally, the growth mechanism of $\mathrm{GaN}$ by ammonothermal growth is explained as follows: 1) a nutrient, such as polycrystalline $\mathrm{GaN}$ or metallic $\mathrm{Ga}$, is placed in a nutrient region and dissolved in supercritical ammonia under a high pressure (100-400 $\mathrm{MPa})$ and a high temperature $\left.\left(400-600{ }^{\circ} \mathrm{C}\right) ; 2\right)$ the convective flow of the solvent (i.e., supercritical ammonia) transports the dissolved solute to a seed region; 3) the solvent becomes supersaturated in the seed region under a different temperature and/or pressure from those in the nutrient region; and 4) $\mathrm{GaN}$ crystallizes on seed crystals. Figure 1 


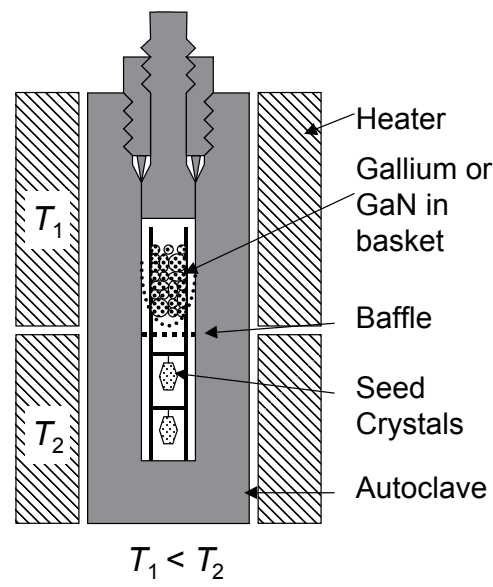

(a)

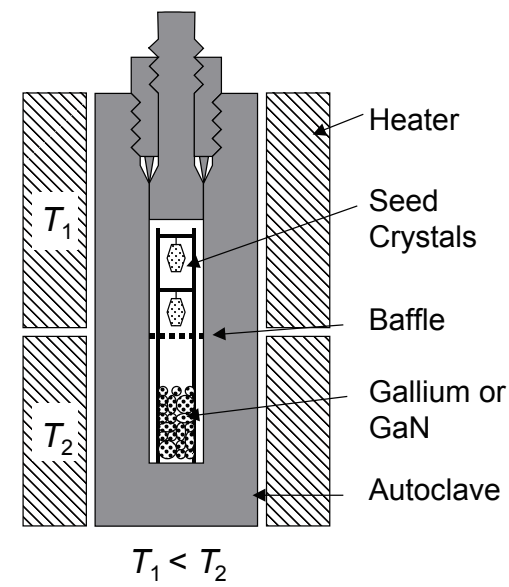

(b)

Fig. 1. Schematic drawings of ammonothermal growth setups. (a) Configuration for basic ammonothermal growth and (b) configuration for acidic ammonothermal growth. Note the differences in the nutrient and seed positioning.

shows schematic drawings of typical ammonothermal growth setups. An autoclave that houses internal components and source materials is heated by an external furnace. The furnace elements are divided into a few regions to achieve a temperature difference: the lower region is usually maintained at a higher temperature than the upper region. The configuration of internal components differs depending on the acidity of the supercritical ammonia because the temperature dependence of the solubility varies depending on the acidity of the supercritical ammonia. ${ }^{(13)}$ In the case of basic ammonothermal growth, the nutrient is placed in the upper region of the autoclave and seed crystals are placed in the lower region, as shown in Fig. 1(a). In contrast, seed crystals are placed in the upper region and the nutrient is placed in the lower region for acidic ammonothermal growth, as shown in Fig. 1(b).

\subsection{Experimental procedure}

Ammonothermal autoclaves made of a Ni-Cr-based superalloy with 1" inner diameter were used to grow crystals discussed in this article. The inner space of the autoclave was divided into two regions: a nutrient region and a seed region with a baffle. The growth temperature was in the range from 500 to $600{ }^{\circ} \mathrm{C}$, and the resulting ammonia pressure was in the range from 100 to $300 \mathrm{MPa}$. Polycrystalline GaN or metallic Ga was used as the nutrient, and free-standing GaN platelets were used as seed crystals. Both the polycrystalline $\mathrm{GaN}$ and free-standing $\mathrm{GaN}$ platelets were prepared by a vapor-phase growth method. The growth rate was in the range from 10 to $400 \mu \mathrm{m} / \mathrm{d}$ depending on the growth conditions. Bulk GaN crystals having thicknesses of $5 \mathrm{~mm}$ were routinely obtained. The bulk GaN crystals were sliced with a multiple wire saw and the sliced wafers were lapped with diamond slurry and polished with colloidal silica. 
The thicknesses of seeds, grown crystals and sliced wafers were measured with a micrometer. The structural quality was evaluated from the full width at half maximum (FWHM) of the X-ray rocking curves (XRCs) obtained from both 002 and 201 diffractions. The XRCs were collected using a high-resolution four-axis X-ray diffractometer (Philips) with a $\mathrm{Cu}$ anode operated at $40 \mathrm{~mA}$ and $45 \mathrm{keV}$ and a fourcrystal Ge (002) monochromator. By using a shallow incident X-ray beam to the c-plane surface, 114 diffraction was recorded in 2 theta-omega scans to evaluate the removal of a surface-damaged layer after CMP. White-beam synchrotron radiation X-ray topography (SR-XRT) was used to estimate the dislocation density. The 0006 topograph was recorded over a $500 \times 500 \mu \mathrm{m}^{2}$ area in back reflection geometry with the crystal tilt of $8^{\circ}$. Impurities in the grown crystals were quantified by secondary ion mass spectroscopy (SIMS) carried out at Evans Analytical Group, LLC. The optical absorption of the crystals was measured with a spectrophotometer (Shimadzu).

\section{Properties of Bulk GaN Crystals and Wafers}

\subsection{Current status of bulk GaN growth}

Figure 2 shows an example of bulk GaN crystals routinely grown at SixPoint. The lateral size is $5-15 \mathrm{~mm}$ and the thickness is $3-10 \mathrm{~mm}$. The FWHM of the XRCs from both 002 and 201 diffractions ranges from a few tens of arcsec to a few hundred arcsec depending on the growth conditions. Figure 3(a) presents an example of the XRC from the 002 diffraction. The FWHM was 31 arcsec. The XRC from the 201 diffraction showed a similar FHWM value (38 arcsec) as shown in Fig. 3(b). This phenomenon is not commonly observed for the heteroepitaxial growth of GaN thin films in which edge-type and mixed-type dislocations are dominant. We consider that increasing the thickness of the bulk crystals improves the microstructure, particularly in terms of reducing the edge component of dislocations.

$\mathrm{X}$-ray topography was observed to estimate the density of dislocations. As presented in Fig. 4, the observed dislocations are primarily screw-type dislocations (white dots in the image). The density of dislocations was estimated to be $4.0 \times 10^{4} \mathrm{~cm}^{-2}$.

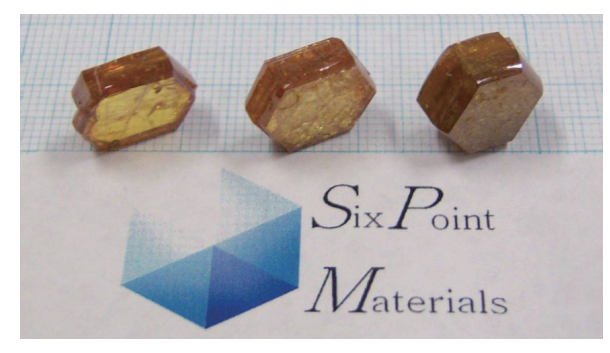

Fig. 2. (Color online) Examples of GaN bulk crystals grown by the ammonothermal growth method. 


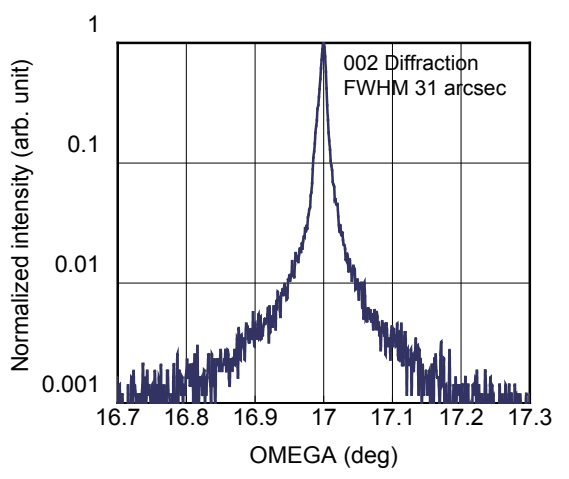

(a)

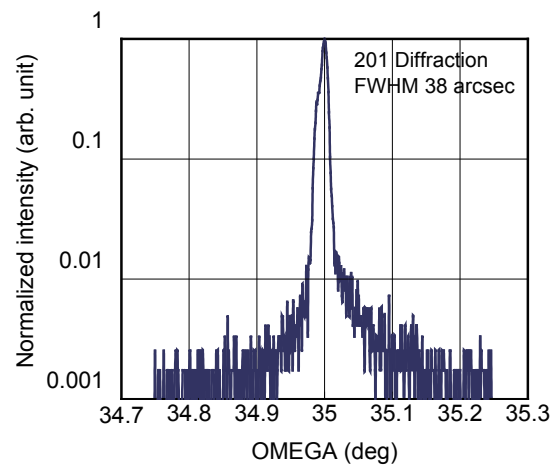

(b)

Fig. 3. (Color online) Omega scan of XRC from a bulk GaN crystal. (a) 002 diffraction and (b) 201 diffraction.

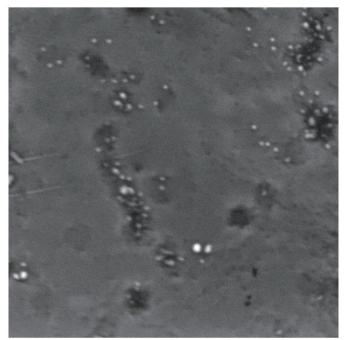

Fig. 4. Synchrotron radiation X-ray topography observed in back reflection geometry. The white dots represent dislocations and the density is $4.0 \times 10^{4} \mathrm{~cm}^{-2}$.

The optical absorption at $450 \mathrm{~nm}$, which is a typical emission wavelength of blue LEDs for phosphor-excited white LEDs, ranges from 4 to $20 \mathrm{~cm}^{-1}$, depending on the growth conditions. For LED applications, the optical absorption of a substrate must be minimized to increase the external quantum efficiency. To investigate the origin of the crystal color, GaN crystals intentionally doped with oxygen were grown by the ammonothermal growth method. Figure 5 shows the relationship between the optical absorption coefficient at $450 \mathrm{~nm}$ and the oxygen concentration measured by SIMS. The optical absorption shows a clear correlation with the oxygen concentration in the crystal. By minimizing the amount of oxygen in the crystal through the optimization of the growth conditions, we succeeded in reducing the absorption coefficient to $4 \mathrm{~cm}^{-1}$ at $450 \mathrm{~nm}$, as shown in Fig. 5. Since HVPE-grown GaN substrates have an absorption coefficient of 1 to $2 \mathrm{~cm}^{-1}$, we are confident that further optimization of the growth conditions will achieve an ammonothermal GaN substrate with transparency comparable to that of HVPE-grown GaN substrates. 


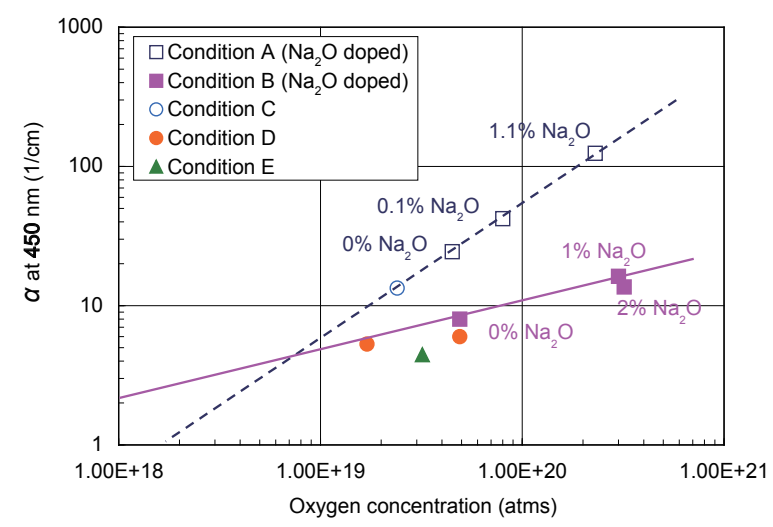

Fig. 5. (Color online) Relationship between optical absorption coefficient at $450 \mathrm{~nm}$ and oxygen concentration.

\subsection{Issues in wafer processing techniques}

Bulk GaN crystals grown by the ammonothermal method are readily sliced into wafers. However, the crystals typically contain cracks owing to a high level of stress (Fig. 6). When a low-quality seed crystal is used under an unoptimized growth condition, a crystal contains numerous small cracks as shown in Fig. 6(a). We have been improving the seed quality as well as the growth condition to reduce the density of cracks in crystals [Fig. 6(b)]. If a crystal with cracks is sliced with a wire saw, the wafer surface shows wide and deep crack lines caused by diamond abrasives. It is difficult to remove the deep crack lines by lapping and polishing. Thus, it is important to eliminate a crack in the bulk GaN.

The sliced wafers are typically lapped with diamond slurry followed by CMP using colloidal silica. To ensure a damage-free surface after CMP, it is important to characterize the surface. Surface quality is commonly evaluated by atomic force microscopy (AFM) or surface interferometry. The observation of the surfaces by these methods, however, does not guarantee a damage-free surface. ${ }^{(14)}$ To evaluate the atomic arrangement of the surface, a certain type of diffraction method [e.g., reflection highenergy electron diffraction (RHEED)] must be utilized. Although RHEED can confirm the surface atomic arrangement, the usage of high vacuum impedes the high throughput. We have developed a method utilizing 114 X-ray diffraction observed with a low-angle incident beam. By taking the ratio of the peak intensity from 114 diffraction to that from 002 diffraction, we found it possible to evaluate the surface finishing of the wafer, as shown in Fig. 7 and Table 1. The as-sliced GaN wafer shows an extremely low 114 peak intensity, although it shows a similar 002 intensity to a wafer obtained after CMP. The reduced peak intensity arises from random scattering of the incident X-ray beam by the surface damage layer. Checking the 114 peak intensity after CMP ensures an ordered atomic arrangement on the GaN surface. 


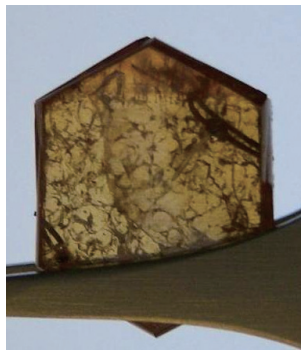

(a)

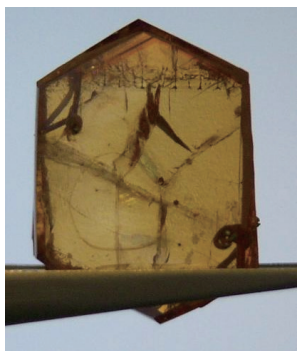

(b)

Fig. 6. (Color online) Cracks generated in the crystals. (a) Numerous small cracks under one condition. (b) Reduced crack density under improved growth condition.

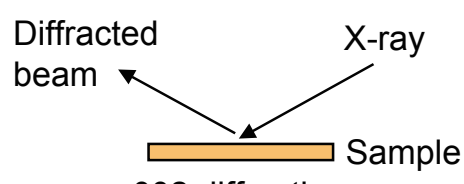

002 diffraction

(a)

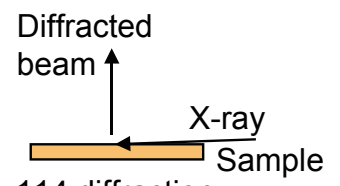

114 diffraction

(b)

Fig. 7. (Color online) Schematics of 002 and 114 diffractions. (a) 002 diffraction commonly used to characterize crystal coherency. (b) 114 diffraction using shallow-angle X-ray incident beam to evaluate the surface damage layer.

Table 1

Peak intensities of 002 and 114 X-ray diffractions for an as-sliced wafer and a wafer obtained after CMP.

\begin{tabular}{lccc}
\hline Sample & $\begin{array}{c}\text { Peak height from } \\
002 \text { diffraction }\end{array}$ & $\begin{array}{c}\text { Peak height from } \\
114 \text { diffraction }\end{array}$ & Ratio 114/002 \\
\hline As sliced & $31266 \mathrm{cps}$ & $40 \mathrm{cps}$ & $1.3 \times 10^{-3}$ \\
After CMP & $29565 \mathrm{cps}$ & $7855 \mathrm{cps}$ & $2.7 \times 10^{-1}$ \\
\hline
\end{tabular}

\section{Conclusions}

In this article, we reviewed the ammonothermal growth of $\mathrm{GaN}$, which has the potential to realize low-cost, high-quality GaN substrates for various devices such as high-power LEDs and high-power transistors. Currently, small bulk GaN crystals show an excellent microstructure as well as an improved crystal color. Further optimization of the crystal growth conditions would achieve transparent, crack-free GaN crystals. A few issues in wafer fabrication processes are presented. As for slicing the wafers with a wire saw, it is important to eliminate cracks in the crystals because they are deepened and widened during slicing. Evaluation of CMP finishing requires diffraction to ensure atomic ordering on the surface. We demonstrated the successful evaluation of CMP finishing using an X-ray 2 theta-omega scan of 114 diffraction with a shallow incident beam to the c-plane surface. 


\section{Acknowledgements}

Part of this work was conducted with support from the Small Business Innovative Research (SBIR) program by the National Science Foundation (NSF), grant number IIP-1142356. The SR-XRT was measured by Dr. Sintonen and Dr. Suihkonen at Aalto University, Finland.

\section{References}

1 K. Motoki, T. Okahisa, R. Hirota, S. Nakahata, K. Uematsu and N. Matsumoto: J. Cryst. Growth 305 (2007) 377.

2 K. Fujito, S. Kubo, H. Nagaoka, T. Mochizuki, H. Namita and S Nagao: J. Cryst. Growth 311 (2009) 3011.

3 D. Hanser, L. Liu, E. A. Preble, K. Udwary, T. Paskova and K. R. Evans: J. Cryst. Growth 310 (2008) 3953.

4 S. Porowski: MRS Internet J. Nitride Semicond. Res. 4S1 (1999) G1.3.

5 T. Inoue, Y. Seki, O. Oda, S. Kurai, Y. Yamada and T. Taguchi: Phys. Status Solidi B 223 (2001) 15.

6 H. Yamane, M. Shimada, T. Sekiguchi and F. J. DiSalvo: J. Cryst. Growth 186 (1998) 8.

7 F. Kawamura, M. Morishita, K. Omae, M. Yoshimura, Y. Mori and T. Sasaki: Jpn. J. Appl. Phys. 42 (2003) L879.

8 R. Dwiliński, R. Doradziński, J. Garczyński, L. Sierzputowski, M. Palczewska, A. Wysmolek and M. Kamińska: MRS Internet J. Nitride Semicond. Res. 3 (1998) 25.

9 D. R. Ketchum and J. W. Kolis: J. Cryst. Growth 222 (2001) 431.

10 A. P. Purdy, R. J. Jouet and C. F. George: Cryst. Growth Des. 2 (2002) 141.

11 R. Dwiliński, R. Doradziński, J. Garczyński, L. Sierzputowski, A. Puchalski, Y. Kanbara, K. Yagi, H. Minakuchi and H. Hayashi: J. Cryst. Growth 310 (2008) 3911.

12 T. Hashimoto, F. Wu, J. S. Speck and S. Nakamura: J. Cryst. Growth 310 (2008) 3907.

13 D. Ehrentraut, E. Meissner and M. Bockowski (ed.): Technology of Gallium Nitride Crystal Growth (Springer, Berlin, 2010) Chaps. 8 and 9.

14 H. Aida, H. Takeda, K. Koyama, H. Katakura, K. Sunakawa and T. Doi: J. Electrochem. Soc. 158 (2011) H1206. 